\section{AB0307 PREDICTIVE VALUE OF THE BASELINE CLINICAL, LABORATORY AND ECHOSONOGRAPHIC PARAMETERS OF RA ACTIVITY IN PROGRESSION OF STRUCTURAL DAMAGE IN DMARDS NAÏVE EARLY RA PATIENTS - 6 MONTHS FOLLOW-UP-}

S.Z. Prodanovic ${ }^{1}$, J. Colic ${ }^{2}$, M. Sefik-bukilica ${ }^{3}$, G. Radunovic ${ }^{2}$, N. Damjanov ${ }^{4}$ ${ }^{1}$ clinical IVb; ${ }^{2}$ clinical IVa; ${ }^{3}$ laboratory demartment, ${ }^{4} \mathrm{Head}$ of Institute, Institute of Rheumatology, Belgrade, Serbia

Background: The structural damage of RA usually develops within the first two years of disease and the risk of joint destruction is still difficult to predict ${ }^{1}$ Objectives: To assess predictive value of the clinical, laboratory and echosonographic parameters activity of early RA in progression of structural damage in DMARDs/glucocorticoid naïve patients in the first 6 months.

Methods: Sixty-five pts. ( 56 females, mean age $53 \pm 14.1$ years) with early RA (EULAR/ACR 2010 criteria) and symptoms duration of $\leq 1$ years. (mean duration of 3.6 months) were included during the 2012-14 years. and followed up 6 months. Patients were DMARDs/glicocorticoid naïve and had no X-ray visible structural damage. The ESR, CRP, RF, ACPA and MMP3 were measured. DAS28 index was calculated. US assessment was performed blindly to patient's medical history, on the same day when early RA diagnosis was established and repeated after 6 months, using $18 \mathrm{MHz}$ linear probe by ESAOTE My Lab 70 machine. Presence of bone erosions and Power Doppler (PD) signal, were recorded at each hand's joint, as well as at MTP1-5 joints of both side, according to OMERACT US group definition. The semi quantitative method (0-3) was applied for assessing US synovitis and total Power Doppler joint score (TPDJs)/ pts. was calculated.

Results: Fifty-nine pts. had finding of US bone erosions at baseline visit and 62 pts had it after 6 months. The significant increase of bone erosions and significant decrease of TPDJs/pts were found after follow-up (2.2. vs. 3.1 respectively; 10. vs. 4.5 respectively; Wilcoxon test: $p<0.001)$. There was no statistical significant difference between the groups of pts. with (42 pts.) and without ( 23 pts.) new $(\geq 1)$ US bone erosion after 6 months regarding value of ESR (41. vs. 39; $p=0.973$ ), CRP (18. vs. 11; $p=0.255$ ), RF (82. vs. $114 ; p=0.652$ ), ACPA (184. vs. 319 ; $p=0.784$ ) MMP3 (110. vs. 83; $p=0.245$ ), DAS28 (5.7. vs. $5.3 ; p=0.269$ ), total number of bone erosions (2. vs. $2 ; p=0.06$ ) and TPDJs/pts (10. vs. $12 ; p=0.831)$. Univariant logistic regression analysis showed significant predictive value for US bone erosions finding at baseline visit OR $0.68(0.48-0.98), p=0.04$ for progression of structural damage after 6 months of follow up but not for value of: ESR: OR 1.28 (0.45-3.61), $p=0.635$; CRP: OR 2.75 (0.95-7.93), $p=0.06$; RF: OR 0.83 (0.30-2.30), $p=0.726$; ACPA: OR 0.96 (0.33-2.78), $p=0.904$; MMP3: OR 1.28 $(0.42-3.88), p=0.656$; DAS28: OR $1.23(0.82-1.86), p=0.311$ and TPDJs/pts OR $0.98(0.93-1.02), \mathrm{p}=0.344$.

Conclusions: Initial finding of US bone erosion is the most important risk factor for progression of structural damage with our DMARDs/glucocorticoid naïve early RA patients in the first 6 months of disease duration.

\section{REFERENCE:}

[1] Morel J, Combe B. How to predict prognosis in early rheumatoid arthritis. Best Pract Res Clin Rheumatol 2005;19:137-46.

Disclosure of Interest: None declared

DOI: 10.1136/annrheumdis-2018-eular.3290

\section{AB0308 IMPORTANCE OF PATIENT EDUCATION FOR MANAGEMENT OF RHEUMATOID ARTHRITISPATIENTS}

S.H. Senara ${ }^{1}$, W.Y. Abdel wahed ${ }^{2}$, S.E. Mabrouk ${ }^{2} .{ }^{1}$ Rheumatology and Rehabilitation; ${ }^{2}$ Community, Fayoum University- Egypt, Fayoum, Egypt

Background: People living with chronic diseases such as rheumatoid arthritis (RA) are extremely in need to Patient education (PE) which enables them to cope and adapt with their disease and treatments. PE comprises all educational activities provided for patients, including aspects of health and therapeutic education and promotion. Evolutions have been seen at the last five decades of the patient/ clinicians relationship, where the patients can share in decision-making (Mwidimi Ndosi1 and Ade Adebajo, 2015.

Objectives: To evaluate the effect of PE program following the eight evidencebased EULAR-2015 recommendations in the management of RA patients.

Methods: Comparative study with randomised parallel two arms with ratio (1:1) conducted on 100 rheumatoid arthritis (RA) patients (both sexes), aged 19-71 years patients were carried out at the Department of Rheumatology and Rehabilitation -faculty of medicine of Fayoum University, Egypt. Patients are excluded if they had evidence of mental disorder or psychiatric diseases. Patients can leave the study at any time for any reason. Two main comparable groups; group I received health education through designed Health education program, Group II were not prone to health education program. Disease activity and disability of patients were assessed prior to the commencement of the program, (visit I preintervention), 3 months later (Visit II post-intervention) and 6 months after the first visit (Visit III post-intervention). Intervention: A PE program designed by authors addressed EULAR 2015 recommendation of patient education and tailored according to each patient condition. Groups of 8-10 participants randomised to intervention arm attended 1 session each week for 6 consecutive weeks, with each one hour in duration, and then one session every two weeks until the second assessment visit (Visit II) and then every month until the second assessment visit (Visit III).

Results: While 50 patients of group I continued at the end of the study, out of 50 patients of group II, 36 patients were available at 2nd visit, and only 24 patients were available to be assessed at the 3rd visit. By comparing lab investigation and outcome scores at follow up visits; although no significant difference between the two study groups regarding lab investigations, DAS28 and HAQ scores at start of study, difference was reported in follow up visits that a significant decrease of these labs and scores were reported in Group I, while no difference reported in Group II.

Abstract AB0308 - Table 1. Lab and measuring scores comparison between Gl and GIl at 3nd Visit

\begin{tabular}{|c|c|c|c|c|c|c|}
\hline \multirow{2}{*}{$\begin{array}{l}\text { Lab } \\
\text { investigation } \\
\text { ESR }\end{array}$} & & \multicolumn{2}{|c|}{ G I } & \multicolumn{2}{|c|}{ G II } & \multirow[t]{2}{*}{$\begin{array}{c}P \\
\text { value }\end{array}$} \\
\hline & & $\underset{(=50)}{\mathrm{N}}$ & $\%$ & $\underset{(=24)}{N}$ & $\%$ & \\
\hline & Positive & 20 & 40.0 & 23.0 & 95.8 . & 0.00 \\
\hline & Negative & 30 & 60.0 & 1 & & 4.2 \\
\hline \multirow[t]{2}{*}{ CRP } & Positive & 19.0 & 38.0 & 19.0 & 79.2 & 0.001 \\
\hline & Negative & 31 & 62.0 & 5 & 20.8 & \\
\hline \multirow[t]{2}{*}{ RF } & Positive & 50.0 & 100.0 & 19 & 79.2 & 0.003 \\
\hline & Negative & 0 & 0.0 & 5 & 10.8 & \\
\hline DAS28 & $\begin{array}{c}\text { Mean } \pm S D \\
\text { range }\end{array}$ & \multicolumn{2}{|c|}{$\begin{array}{l}1.6 \pm 0.4 \\
1.2: 2.3\end{array}$} & \multicolumn{2}{|c|}{$\begin{array}{c}\text { 3. } 6 \pm 1.5 \\
1.3: 5.1\end{array}$} & 0.00 \\
\hline $\mathrm{HAQ}$ & $\begin{array}{l}\text { Mean } \pm S D \\
\text { range }\end{array}$ & & & \multicolumn{2}{|c|}{$\begin{array}{c}\text { 59. } 8 \pm 23.13 \\
23: 88\end{array}$} & 0.00 \\
\hline
\end{tabular}

Conclusions: Patient education (PE) interventions in patients with (RA) documented significant improvements in behaviour, pain, disability of those patients.

\section{REFERENCE:}

[1] Mwidimi Ndosi1, Ade Adebajo. Patient education in rheumatoid arthritis: is the needs-based approach the way forward? Received:Clin Rheumatol 2015;34:1827-1829. doi:10.1007/s10067-015-3063-2

Disclosure of Interest: None declared

DOI: 10.1136/annrheumdis-2018-eular.2246

\section{AB0309 NEED TO A WALK TO THE COMPLETE REMISSION; FOOT AND/OR ANKLE ARTHRITIS IMPEDE COMPLETE REMISSION IN RHEUMATOID ARTHRITIS -PART 1 , CROSS-SECTIONAL STUDY FROM KOREAN COLLEGE OF RHEUMATOLOGY BIOLOGICS (KOBIO) REGISTRY}

S.H. Chang ${ }^{1, *}$, S.W. Lee ${ }^{2}$, M.I. Kang ${ }^{3}$, H.W. Kim ${ }^{4}$, on behalf of Korean College of Rheumatology BIOlogics (KOBIO) registry. ${ }^{1}$ Division of Rheumatology, Department of Internal medicine, Soonchunhyang University, College of Medicine, Seongnamsi; ${ }^{2}$ Soonchunhyang Univ Choenan Hosp; ${ }^{3}$ Dankook Univ Hospital, Cheonan; ${ }^{4}$ Bundang Seoul National Univ. Hospital, Seongnam-Si, Korea, Republic of Ireland

Objectives: To determine the prevalence of foot synovitis, and the most stringent disease activity index reflecting complete remission among patients with rheumatoid arthritis in Korea.

Methods: We conducted a cross-sectional study using data from the Korean College of Rheumatology BIOlogics (KOBIO) registry. Foot arthritis defined as having one or more tender or swollen joints in ankle and/or 1st to 5th metatarsal joints. Functional status and disease activity evaluated by the routine assessment of patient index data3 (RAPID3), the disease activity score 28 ESR (DAS28), the simplified disease activity index (SDAI), the clinical disease activity index (CDAI), and the ACR/EULAR Boolean criteria.

Results: Baseline data of 2046 patients were analysed. Patients with foot arthritis showed significantly younger age at the diagnosis, longer disease, duration, 
higher DAS-28/SDAI/CDAI/RAPID-3, lower rate of ACR/EULAR Boolean criteria remission, use of higher dose of glucocorticoid, and higher rate of bone erosion not only on foot but also hand X-rays. Among those patients, 174 patients $(8.5 \%)$ were in DAS 28 clinical remission. Twenty-one of 174 patients (12.1\%) had foot arthritis, who showed higher swollen and tender joint count, RAPID-3 score, and patients' global assessment but not physicians' global assessment than those without foot arthritis. Among patients with foot arthritis, rate of complete remission was the highest in patients with CDAI $(66.7 \%)$.

Conclusions: In patients with rheumatoid arthritis, foot and/or ankle arthritis is associated with high disease activity, not achieving complete remission despite of various clinical remission criteria and discordance between patients' and physicians' global assessment.

Disclosure of Interest: None declared

DOI: 10.1136/annrheumdis-2018-eular.4525

\section{AB0310 USING TREAT-TO-TARGET STRATEGY BY DETERMINING PHYSICAL DISABILITY AND GLUCOCORTICOID REDUCTION STRONGLY INFLUENCE FUNCTIONAL REMISSION IN RHEUMATOID ARTHRITIS}

T. Hagiwara, K. Kamada, N. Namura. Rheumatology, Takarazuka City Hospital, Takarazuka, Japan

Background: The initial target in the treatment of rheumatoid arthritis $(R A)$ is to achieve clinical remission (CR) through Boolean definition and/or index-based criteria and sustain $\mathrm{CR}$, and the final target is to maximise long-term health-related quality of life (HRQoL) through arthritis control, joint damage prevention, function normalisation and social participation. ${ }^{1}$

Objectives: We aimed to determine the factors that inhibit the achievement of functional remission $(\mathrm{FcR})$ in terms of HRQoL.

Methods: A total of 227 patients with RA who had underwent first treatment between October 2014 and December 2017 and had not changed/added another disease-modifying anti-rheumatic drugs (DMARDs) for 12 weeks before the observation day were examined. We used daily-life function and social activity participation to evaluate HRQoL. We adopted the Health Assessment Questionnaire Disability Index (HAQDI) as daily-life functional assessment and EuroQoL 5 dimensions -5 levels (EQ5D) for health status with considerable potential assessment. FcR was defined in this study as HAQDI $\leq 0.5$ and EQ5D $\geq 0.867$ " 0.867 is the lowest QoL score when only one category permits $\leq 2$ of the 5 levels, but others need 1 in all five categories". We investigated their age at RA onset, sex, Steinbrocker stage and functional class, HAQDI, disease activity level, rheumatoid factor, anti-cyclic citrullinated peptide antibody at the first consultation, age, disease activity level, HAQDI, EQ5D, and status of methotrexate (MTX), glucocorticoids (GCs) and biologic/target synthetic DMARD (b/ts-DMARD) use at the last observational day. First, the assumed remissions were analysed using the $\mathrm{FcR}$ as a purpose variable for these factors. Subsequently, the odds ratio and $95 \%$ confidence interval $(95 \% \mathrm{Cl})$ were examined using multiple logistic regression analysis for the statistically significantly different factors and risk factors.

Results: The CR achievement rate at the last observational day by Boolean definition and Simple Disease Activity Index were $40.5 \%$ and $50.2 \%$, respectively. The achievement ratio of $\mathrm{HAQ}-\mathrm{DI} \leq 0.5$, EQ5D $>0.867$ and $\mathrm{FcR}$ was $73.1 \%$, $48.5 \%$, and $46.7 \%$, respectively. The differences in disease duration, stage, class and HAQDI at the time of the first interview; state of MTX, GCs and b/ts-DMARD use; and age at the last observational day for the achievement of FcR were statistically significant. The odds ratios, as determined by multiple logistic regression analysis of the above-mentioned results, were $1.034(95 \% \mathrm{Cl} 0.982-1.088$, $\mathrm{p}=0.202$ ) for disease duration (per 1 year), $1.576(95 \% \mathrm{Cl} 1.257-1.977, \mathrm{p}<0.001)$ for HAQDI at first interview (per 0.5), $0.615(95 \% \mathrm{Cl} 0.277-1.365, \mathrm{p}=0.232$ ) and $4.943(95 \% \mathrm{Cl} 1.683-14.524, \mathrm{p}<0.01)$ for GCs state (non-use vs temporal use and non-use vs continuous use, respectively), and 1.164 (95\% Cl 1.037-1.307, $\mathrm{p}<0.05)$ for age at last observational day.

Conclusions: HRQoL is important as they will influence future treatment strategy. Our results indicated the importance of functional assessment at first interview and demonstrated how to use GCs for the treatment of RA. Ageing always contributes to patients' frailty, and it is unavoidable it. To achieve FcR, functional assessment should be performed during the first interview and short-term use of $\mathrm{GC}$ is useful for prompt functional recovery, in consideration of ageing.

\section{REFERENCE:}

[1] de Wit MP, et al. ARD 2011;70(6):891-895. doi:10.1136/ard.2010.14662

Disclosure of Interest: None declared

DOI: 10.1136/annrheumdis-2018-eular.2810

\section{$\mathrm{AB} 0311$ \\ DETERMINANTS OF NON-NOCICEPTIVE PAIN IN RHEUMATOID ARTHRITIS}

T.M. Rocha, S. Pimenta, M. Bernardes, A. Bernardo, M. Barbosa, R. Lucas, L. Costa. Rheumatology, Centro Hospitalar de São João, Porto, Portugal

Background: A neuropathic component (NP) of Rheumatoid Arthritis (RA) pain was described in nearly a third of the patients. Radiographic damage is a reflection of cumulative disease activity and other pathophysiological processes. Some clinical predictors of RA NP were recently identified by our group, but association and adjustment for radiographic damage were not studied.

Objectives: To estimate the clinical predictors of NP in RA patients adjusting for their radiographic damage.

Methods: Cross-sectional study was performed with RA patients followed at our Rheumatology department. Patients with diagnosed neuropathy or non-RA risk factors for NP were excluded. Selected patients were evaluated in a medical visit. Demographic and clinical data were collected and two questionnaires were applied to assess NP: the Leeds Assessment of Neuropathic Symptoms (LANSS) and the painDETECT (PDQ). Wrists, hands and feet radiographic studies from the previous 12 months were classified according to the modified van der Heijde Sharp's method by one trained reader, blinded for patient clinical variables and treatment allocation. Univariate and multivariate logistic regression were performed adjusting for global radiographic score (GS). Significance level was set as $<0.05$.

Results: Ninety one RA patients were included. Seventy (77\%) were women, with a mean (SD) age of 55.6 (10.8) years and median disease duration of 12 years, ${ }^{2-41} 84 \%$ patients were seropositive for Rheumatoid Factor and/or ACPA $85(93 \%)$ were treated with DMARDs and $41 \%$ with a biological DMARD (bDMARDs). The mean (SD) DAS28 4V CRP was 3.15 (0.77). The median join erosion score was 28 (range: $3-143$ ) and the median joint space narrowing (JN) was 46 (range: 10-133). Forty-two (46\%) patients had LANSS NP ( $\geq 12)$ and $29 \%$ had a possible/likely NP in the PDQ $(>12)$. JN was a significant negative predicto of LANSS NP (OR: 0.98, $\mathrm{p}=0.02$ ). After adjusting for $\mathrm{GS}$, gender was not associated with NP. Pain VAS, patient global activity and the tender joint count were positive predictors of NP by both tests. Swollen joint count, ESR or CRP levels were not significantly associated with NP. DAS28 CRP was a significant positive predictor of NP by both tests (OR 1.89 for LANSS and OR: 2.06 for PDQ, $\mathrm{p}<0.05$ ); as well as the HAQ score (OR: 2.68 and OR: 4.85, respectively, $p<0.05$ ). Positivity for ACPA was a negative predictor of LANSS NP (OR: 0.31, $p=0.048$ ), as previously described. Current methotrexate treatment had lower odds of LANSS NP (OR: $0.35, p=0.04$ ) but did not remained significant after adjustment for DAS28 CRP. Previous/current Hydroxychloroquine (HCQ) treatment was once more a negative predictor for PDQ NP (OR: $0.11, p=0.04$ ) and remained significant after adjustment for DAS28 CRP. Previous/current leflunomide (LFN) was newly a positive predictor of NP in both tests (OR: 3.41 for LANSS and OR: 2.95 for PDQ, $\mathrm{p}<0.05$ ), persisting after disease activity adjustment for LANSS NP. No other associations were found.

Conclusions: Consistently with our previous data, this study supports an association between NP and disease activity/functional scores but not with objective inflammatory measures. Possible increased risk of NP in LFN treated patients was newly pointed and protective role of ACPA positivity and $\mathrm{HCQ}$ was reinforced.

\section{REFERENCES}

[1] Christensen AW, et al. Scand J Rheumatol 2016;1-9.

[2] Martins-Rocha T, et al. Ann Rheum Dis, 2017;76(suppl 2):1177.

Disclosure of Interest: T. Rocha Grant/research support from: Portuguese Society of Rheumatology/Alfa Wassermann on May 2015, S. Pimenta: None declared, M. Bernardes: None declared, A. Bernardo: None declared, M. Barbosa: None declared, R. Lucas: None declared, L. Costa: None declared DOI: 10.1136/annrheumdis-2018-eular.5769

\section{AB0312 INFLAMMATORY ACTIVITY APPEARS WELL CONTROLLED IN MOST PATIENTS WITH RHEUMATOID ARTHRITIS (RA) IN CONTEMPORARY RHEUMATOLOGY CARE, BUT JOINT DAMAGE AND DISTRESS REMAIN AS PROBLEMS OF GREATER MAGNITUDE THAN INFLAMMATION}

T. Pincus, I. Castrejon, J.A. Block. Rheumatology, Rush University Medical Center, Chicago, USA

Background: Rheumatologists traditionally use quantitative measures such as swollen and tender joint counts and laboratory tests to assess inflammatory activity. However, structural damage to joints, as well patient distress seen as fibromyalgia, depression, etc., may be important clinical problems for many RA patients, but are described narratively in the medical record rather than estimated 